\title{
EDITORIAL
}

\section{MAMOGRAFÍA EN LA ERA DIGITAL}

La mamografía digital es uno de los mayores avances en el diagnóstico mamario. Está aún en sus inicios, con sólo 8 años de aplicación clínica. No obstante, ya presenta resultados equivalentes a la tecnología analógica e incluso promete mejor detección en algunos sub-grupos de pacientes, como lo evidencia el esperado estudio prospectivo publicado en 2005 por Pisano(1), que demostró una clara superioridad de la mamografía digital en mujeres pre o peri-menopáusicas con mamas densas-heterogéneas, tanto en el diagnóstico del cáncer infiltrante como "in situ".

La calidad de la imagen digital es excelente en términos de resolución y contraste, independiente de las características del parénquima mamario, gracias a su alta definición y a una serie de procesos realizados después de la adquisición, que hacen posible visualizar los diferentes tejidos en forma óptima desde las zonas más densas de la mama hasta la piel, incluyendo la región pezón-aréola. Hemos visto que la mamografía digital mejora la detección de las microcalcificaciones y la nitidez de las imágenes facilita su análisis y clasificación.

Esta tecnología posee además todas las ventajas de la imaginología digital en términos de calidad, eficiencia y flujo de trabajo; por mencionar algunas:

* Integración de la mamografía en el sistema RIS-HIS-PACS existente en los departamentos de radiología, conectándola con todas las modalidades y funciones (almacenamiento de imágenes junto con sus informes, disponibilidad de ambos "on line" para consultas, utilización del sistema de dictado con reconocimiento de voz).

* Interpretación y comparación de estudios mamográficos en pantallas de 5 Mega píxeles que cuentan con una serie de herramientas para amplificar, medir, invertir y alcanzar un óptimo nivel de brillo, contraste y, por lo tanto, una mayor nitidez de las imágenes.

* La rapidez de adquisición, un estudio mamográfico está disponible para su informe en aproximadamente 7-8 minutos, lo que posibilita la entrega inmediata de los resultados.

* Visualización e interpretación en la misma estación de trabajo de todos los estudios mamarios (mamografías, ecografías, resonancia mamaria, procedimientos etc.)

* Acceso a la ficha clínica y a los resultados histológicos de las biopsias.

* Codificación de patologías, creación de base de datos, colección de imágenes patológicas para docencia, auditoría interna, control de procesos y de calidad etc.

* Tele-mamografía para interconsultas, informes a distancia, segunda lectura.

La tecnología digital permite el uso del CAD (Computer Aided Detection) y otras futuras aplicaciones como la Tomosíntesis, Angio-mamografía, fusión de un mamógrafo y un ecógrafo automatizado, entre otras, que son realidad con ensayos clínicos en desarrollo.

La evolución de la mamografía digital es irreversible y progresivamente, es cuestión de tiempo, recursos y voluntad de las instituciones prestadoras de salud, va a sustituir sí o sí, a la tecnología convencional.

Los sistemas digitales tienen dos grandes objetivos: mejorar la imagen al proporcionar una altísima resolución y al mismo tiempo disminuir la dosis para la paciente, comparando con la placa analógica. Para su cumplimiento, debe existir un permanente Control de Calidad de carácter obligatorio.

Chile recientemente se abrió a la realidad digital, varios equipos empezaron a funcionar durante los últimos años. No obstante, no se han puesto en marcha los procesos de Control de Calidad. ¡Un vacío que requiere una pronta solución!

El desarrollo trae nuevos desafíos y, sin duda, el futuro es digital. Todos soñamos con una unidad de imágenes mamarias totalmente integrada, sin placas, lupas, reveladoras ni químicos pero esto requiere cuantiosos recursos y un cambio cultural de gran escala que aún tomará probablemente varios años.

Dra. Eleonora Horvath Editora invitada

\section{Bibliografía}

1. ED. Pisano, C. Gatsonis, E. Hendrick et col. for the Digital Mammographic Imaging Screening Trial (DMIST) Investigators Group. Diagnostic Performance of Digital versus Film Mammography for Breast-Cancer Screening. NEJM 2005; 353: 1773-1783. 